\title{
Expression analysis of genes involved in oxaliplatin response and development of oxaliplatin-resistant HT29 colon cancer cells
}

\author{
C. PLASENCIA ${ }^{1 *}$, E. MARTÍNEZ-BALIBREA ${ }^{2 *}$, A. MARTINEZ-CARDÚS $^{2}$, \\ D.I. QUINN ${ }^{3}$, A. ABAD ${ }^{2}$ and N. NEAMATI ${ }^{1}$ \\ ${ }^{1}$ Department of Pharmaceutical Sciences, School of Pharmacy, University of Southern California, Los Angeles, CA, USA; \\ ${ }^{2}$ Institut Català d'Oncologia, Medical Oncology Service, Hospital Universitari Germans Trias i Pujol, Badalona, \\ Barcelona, Spain; ${ }^{3}$ Department of Medicine, Keck School of Medicine, University of Southern California, \\ Norris Comprehensive Cancer Center, Los Angeles, CA, USA
}

Received January 17, 2006; Accepted March 10, 2006

\begin{abstract}
The interrelationship between platinum resistance and clinical response is not well established. The purpose of this study is to evaluate the expression of 14 genes involved in platinum resistance in a colon cancer cell line (HT29) and its oxaliplatin (OXA)-resistant sublines. Resistant cells exhibited lower expression of many of these genes suggesting that several pathways may be implicated in OXA resistance. Particularly, OXA resistance is accompanied by defects in drug uptake (downregulation of the hCTR1 transporter) and enhanced DNA repair (upregulation of the XPD gene). Our data also confirmed that copper transporters and chaperones
\end{abstract}

Correspondence to: Dr Nouri Neamati, Department of Pharmaceutical Sciences, School of Pharmacy, University of Southern California, Los Angeles, CA 90033, USA

E-mail: neamati@usc.edu

Dr Albert Abad, Institut Català d'Oncologia, Medical Oncology Service, Hospital Universitari Germans Trias i Pujol, C/Ctra. Canyet s/n, 08916 Badalona, Barcelona, Spain

E-mail: aabade@seom.org

${ }^{*}$ Contributed equally

Abbreviations: OXA, oxaliplatin; CDDP, cisplatin; ATP7A, copper transporting P-type adenosine triphosphatase 7A (MNK); ATP7B, copper transporting P-type adenosine triphosphatase 7B (WND); hCTR1, human copper transporter 1; MRP2, multidrug resistance protein 2; COX17, cytochrom oxidase 17; HAH1, human antioxidant 1 homologue; CCS, chaperone for copper/zinc superoxide dismutase; SOD1, copper/zinc superoxide dismutase 1; GST- $\pi$, glutathione S-transferase pi; MT2A, metallothionein IIA; ERCC1, excision repair cross-complementation group 1; XPD, xeroderma pigmentosum group D; XPF, xeroderma pigmentosum group F; CSB, cocaine syndrome group B; SRPK1, serine-rich protein kinase 1

Key words: oxaliplatin, drug resistance, gene expression, colon cancer, real-time quantitative reverse transcriptase-PCR are involved in OXA resistance in colorectal cancer cells as evidenced by the overexpression of ATP7A and CCS in response to OXA exposure. Moreover, increased CCS expression suggests a role for SOD1 in OXA detoxification. Whereas exposure to OXA in HT29 induced significant changes in expression of many of the genes analyzed, only ATP7A, XPD and SRPK1 gene expression was increased in OXA-treated HTOXAR3 resistant cells. To our knowledge, this is the first report of implicating SRPK1 in OXA resistance. This study provides the basis for further evaluation of these putative markers of OXA response and resistance in colorectal cancer patients who are candidates for treatment with OXA.

\section{Introduction}

Oxaliplatin (OXA), a diaminecyclohexane platinum, has demonstrated activity against colorectal cancer in both chemotherapy-naive patients and patients whose disease has progressed on 5-fluorouracil (5FU)-based therapy (1-3). In fact, the addition of OXA to 5FU/folinic acid regimens has increased objective response rates to over $40 \%$ in colorectal cancer patients $(2,4-6)$.

One of the major obstacles in the therapeutic use of platinum analogues is intrinsic or acquired resistance (7-10). Recently, there has been an understanding of the factors involved in platinum resistance $(3,9,10)$. Platinum resistance is a multifactor process that may include alteration in transport (uptake and efflux), drug detoxification, DNA repair, tolerance to DNA damage and apoptosis $(3,9)$. However, there are still major gaps in our understanding of the interrelationship among factors contributing to platinum resistance and its application in the clinic.

The pathways involved in platinum transport remain poorly defined. Most of the studies in the literature assume that these agents enter the cell by passive or facilitated diffusion (11). However, given the degree of hydrophilicity and polarity of platinum agents, particularly cisplatin (CDDP), the involvement of both active and passive transport in drug uptake has been postulated and recently demonstrated in several studies (12-14). More recently, it has been observed 
that cells exhibiting acquired CDDP resistance have deficits in a number of flux functions for divalent metals including copper. Lower concentrations of copper significantly reduced CDDP toxicity, suggesting a role for copper trafficking in the active transport of CDDP (15-18).

The primary uptake transporter for copper is hCTR1 (19). This transporter transfers copper to one of the three known copper chaperones $(20,21)$ : COX17 (that delivers copper to cytochrome $c$ oxidase) (22), CCS (that transfers copper to cytoplasmic and mitochondrial SOD1) and HAH1 (14) that transfers copper to intracellular copper transporters ATP7A and ATP7B located in the Golgi compartment, which sequester copper in order to subsequently efflux it from the cell. Cell lines with low levels of hCTR1 mRNA expression show a reduced sensitivity towards CDDP (23-25) and, therefore, reduced levels of this transporter contribute to resistance to CDDP. The expression of this transporter has also been involved in resistance to other platinum agents, such as carboplatin and oxaliplatin $(14,15)$.

Development of resistance to platinum agents could also be a result of an increase in their efflux (9). Recently, two copper-transporting P-type adenosine triphosphatases, ATP7A and ATP7B, have been identified as specific pumps for platinum compounds in some carcinoma cells (17). ATP7A and ATP7B are members of a class of heavy metal-transporters that pump copper, cadmium, zinc, silver or lead (26). Increased levels of these transporters have been found in several tumors, including ovarian, gastric, breast and colorectal cancer (27-31). Overexpression of ATP7A and ATP7B correlates with CDDP resistance both in vitro and in vivo (14,30-32). These results suggest a role of these transporters in the active efflux of platinum compounds and, therefore, in modulating the cellular pharmacology of these drugs in some tumors. Few studies, however, describe the implications of these transporters in OXA resistance (33).

Cellular detoxification via the glutathione (GSH) system is involved in the metabolism of various cytotoxic agents, including platinum agents (34). The highly reactive hydrated platinum forms readily conjugate with GSH. Conjugation to glutathione limits the toxic effect of $\operatorname{CDDP}(35,36)$. The conjugation reaction can also be catalyzed by GSH-Stransferase $\pi$, GST- $\pi$, which is a member of the protein family involved in cellular detoxification $(3,37)$. Increased levels of GSH and GST- $\pi$ have been detected in CDDPresistant tumor cells, suggesting that inactivation of CDDP contributes to the resistance found in some tumors $(38,39)$. Previously, a connection between levels of GST- $\pi$ GSH, DNA repair enzymes and proteins involved in apoptosis pathways has also been suggested $(40,41)$. Other thiol-rich intracellular proteins, metallothioneins, have also been correlated with CDDP resistance $(42,43)$. However, few studies have described the role of these enzymes in OXA detoxification.

DNA repair has also been proposed as a relevant determinant of cancer cell sensitivity to platinum agents. Nucleotide excision repair (NER) is one of the major pathways for removal of platinum adducts and repairs of DNA damage $(3,44-46)$. It is established that a cellular defect in this pathway results in hypersensitivity to CDDP and that restoration of NER integrity re-establishes sensitivity to normal levels (46). The NER complex is responsible for both global genomic and transcription-coupled nucleotide excision repair (GG-NER and TC-NER, respectively) (44). Only deficiencies in TC-NER have been specifically linked to CDDP sensitivity. In particular, low levels of ERCC1 correlate with better clinical response to CDDP-chemotherapy regimens in non-small cell lung, ovarian and gastric carcinoma $(39,47-50)$. In colon cancer, ERCC1 mRNA levels also are directly related to response and survival in patients receiving oxaliplatin and fluorouracil combination regimens (51).

Finally, several studies have described that serine-rich (SR) proteins and the kinases that phosphorylate them (SRPKs) may also play a role in CDDP-resistance $(52,53)$. SR proteins have an important role in both constitutive and alternative mRNA splicing in mammalian cells (54). The function of the SR family of splicing factors is regulated by phosphorylation. Two highly SR protein-specific kinases, SRPK1 and SRPK2, have been reported to specifically phosphorylate the RS motifs of the SR proteins. It has been described in Saccharomyces cerevisiae mutational disruption of SKY1 (the yeast SRPK1 homologue) confers resistance to CDDP. Inhibition of SRPK1 using antisense oligodoxynucleotides in human ovarian A2780 cells conferred a 4-fold resistance to CDDP (52). This evidence supports the hypothesis that SRPK1 is actively involved in the cytotoxicity of CDDP.

In the present study, we examined whether the levels of expression of genes potentially involved/related with platinum resistance (transport, repair and detoxification) contribute to the emergence of the OXA resistance phenotype in HT29 cells. We especially evaluated the role of genes involved in copper homeostasis to understand their importance in OXA resistance.

\section{Materials and methods}

Cell lines. Human tumor derived colorectal cancer HT29 cells (ATCC, Manassas, VA) were used as the parent cells to obtain OXA-resistant sublines. OXA-resistant cell lines (HTOXAR1, HTOXAR2 and HTOXAR3) were established as a result of continuous exposure to increasing concentrations of OXA for a 10-month period. Cell growth was assessed after 5 days with daily medium changes, by using the methyleneblue technique comparing the sensitive parent and its corresponding OXA-resistant cell line, until resistant population reached doubling times equivalent to corresponding parental cell line HT29. Cytotoxicity testing was performed periodically during the isolation of the resistant sublines as well as during the studies presented in this report. The resistance was found to be stable and the OXA-resistant sublines were maintained in OXA-free medium before experiments. The level of resistance was measured after the cells had been removed from OXA exposure for a minimum of 3 weeks by repeated MTT test.

All cell lines were grown as monolayers in DMEM medium (BioWittaker, Beviers, Belgium) supplemented with $10 \%$ of heat-inactivated fetal calf serum (FBS, Gibco, USA), $400 \mathrm{U} / \mathrm{ml}$ penicillin, $40 \mu \mathrm{g} / \mathrm{ml}$ of gentamicin and $2 \mathrm{mM}$ of L-glutamine (Sigma, St. Louis, MO, USA) and cultured at $37^{\circ} \mathrm{C}$ in a humidified atmosphere of $5 \% \mathrm{CO}_{2}$. Cells were routinely checked for mycoplasm contamination using a PCR-based assay (Stratagene, Cambridge, UK). 
Table I. Oligonucleotide sequences used for quantitative real-time PCR.

\begin{tabular}{|c|c|c|c|c|}
\hline \multirow[b]{2}{*}{ Gene } & \multirow[b]{2}{*}{ Function } & \multirow{2}{*}{$\begin{array}{c}\text { Accesion no. } \\
\text { (GenBank) }\end{array}$} & \multicolumn{2}{|c|}{ Oligonucleotide sequences $\left(5^{\prime} \rightarrow 3^{\prime}\right)$} \\
\hline & & & Forward & Reverse \\
\hline ATP7B & Copper ion transporter & NM_000053 & agtattcaagtgtccttggagaac & gaatgagaactggaaagacctgtg \\
\hline ATP7A & Copper ion transporter & NM_00052 & cctccagctcatctcttcagaa & aggaattacaagtcatgccatcaa \\
\hline hCTR1 & Copper ion transporter & U83460 & tcaccatcacccaaccactt & tcttaaagccaaagtagaaggtca \\
\hline CCS & Copper trafficking & *603864 & acctcaccettggetctgttg & aagggaacaccacagcagc \\
\hline HAH1 & Copper trafficking & U706600 & tcatgccgaagcacgagtt & cttattgaggacccgagagaca \\
\hline COX17 & Copper trafficking & L77001 & cggaagtgactgcggacg & cgccaaaagcagctatgagc \\
\hline MRP2 & Transporter & NM_000392 & gcaaactgttctggtgtggatt & tggtggtagaggatctcttggt \\
\hline GST- $\pi$ & Detoxification & NM_000852 & gccetacaccgtggtctatt & tgtagatgagggagatgtatttgc \\
\hline MT2A & Detoxification & NM_005953 & cgctcccagatgtaaagaa & ggaatatagcaaacggtcac \\
\hline ERCC1 & DNA repair & $* 000003$ & ctgcgggatgagaacgataga & ctcgtcgaggggtatcacaaa \\
\hline XPD & DNA repair & ВC0008346 & gctttgggaaggacgtcgat & cttcaggtcatccaggttgtaga \\
\hline $\mathrm{XPF}$ & DNA repair & NM_005236 & tagttgtggatatgcgtgaatttc & gaggattgaatctccaccetctaa \\
\hline CSB & DNA repair & NM_000124 & agtgcttcagcaggtggac & tgaggtcatccaggaccga \\
\hline SRPK1 & RNA splicing & NM_003137 & acaacacattagccaacttcaaga & ccagccgtggatttcctttg \\
\hline GAPDH & Housekeeping & ВТ006893 & cccetggccaaggtcatccatgacaacttt & cattcaggcgcagagaccactt \\
\hline
\end{tabular}

Drugs. OXA was prepared in water at a concentration of $10 \mathrm{mM}$ stock solution and stored at $-20^{\circ} \mathrm{C}$. CDDP was prepared in physiological serum at a concentration of $3 \mathrm{mg} / \mathrm{ml}$ and stored at $-20^{\circ} \mathrm{C}$. $\mathrm{CuSO}_{4}$ was prepared in water at a concentration of $100 \mathrm{mM}$ stock solution and stored at $4^{\circ} \mathrm{C}$. Further dilutions of each drug were freshly made in media.

Cell viability assay. The cytotoxicity of all drugs was assessed by MTT assay $(55,56)$. Cancer cells were seeded at a density of 2,000 cells/well in 96-well microtiter plates and allowed to attach. Cells were treated with continuous exposure to a corresponding drug for $24 \mathrm{~h}$. Subsequently, the drug was removed and fresh media was added to each well. Cells were allowed to grow for $72 \mathrm{~h}$. MTT (Roche Diagnostics) was then added and doses for each fraction of survival (ranging from $10 \%$ to $90 \%$ of cell viability) were determined in each cell line by the median-effect line method. The data reported represent the mean $\pm \mathrm{SD}$ of a minimum of three independent experiments performed with 8 wells at each drug concentration tested.

Colony-formation assay. Colony-formation assays were also performed to evaluate the resistance degree obtained in these cells as described (57). Briefly, cells were plated in 6-well plates at a density of 100 cells/well and allowed to attach. Next day, serial dilutions of the corresponding drugs (OXA, $\mathrm{CDDP}$ and $\mathrm{CuSO}_{4}$ ) were added for $24 \mathrm{~h}$. After exposure, cells were washed in PBS and cultured in free media until colonies were formed (8-10 days). Cells were subsequently washed, fixed with a glutaraldehyde $1 \%$ solution for $30 \mathrm{~min}$ and stained with a solution of crystal violet (2\%) for $30 \mathrm{~min}$. After staining, cells were thoroughly washed with water. Colonies were imaged on the VersaDoc Imaging System (Bio-Rad) and counted using the Quantity One quantitation software package (Bio-Rad). The data reported represent the mean of a minimum of three independent experiments.

Quantitative gene expression analysis. For determination of basal levels, resistant cells were maintained free of OXA for several weeks before the evaluation of the gene expression. Total RNA from cells was extracted using TRIzol (Invitrogen) and cDNA was synthesized with $2.5 \mu \mathrm{g}$ of total RNA, random hexadeoxynucleotide primer (Invitrogen) in $20 \mu 1$ of a solution containing reverse transcriptase and stored at $-20^{\circ} \mathrm{C}$ until use. Real-time quantitative PCR was carried out in the iCycler thermocycler (Bio-Rad). The amplification reaction mixture (15 $\mu 1)$ contained cDNAs, forward and reverse primers, and PCR SYBR-Green IQmix (Bio-Rad). Two replicate wells per each gene per each cell line were included in each plate and a minimum of three independent experiments were performed. The thermocycler parameters were as follows: $50^{\circ} \mathrm{C}$ for $2 \mathrm{~min}$, $95^{\circ} \mathrm{C}$ for $10 \mathrm{~min} ; 35$ cycles of $95^{\circ} \mathrm{C}$ for $10 \mathrm{sec}, 55^{\circ} \mathrm{C}$ for $20 \mathrm{sec}$, $72^{\circ} \mathrm{C}$ for $20 \mathrm{sec}$. The oligonucleotide sequences used are listed in Table I. Relative gene expression quantification was calculated according to the comparative threshold cycle method (2- $\left.2^{-\Delta \mathrm{Ct}}\right)$ (58) using GAPDH as an endogenous control and RNA from HT29 parental cell lines as a reference.

For the OXA-treated experiment, HT29 and HTOXAR3 cells were seeded in duplicate flasks. One of the flasks from each cell line was exposed for $48 \mathrm{~h}$ to the drug at the dose with which we previously induced resistance in HTOXAR3 cells $(14 \mu \mathrm{M})$. Untreated HT29 and HTOXAR3 cells were maintained in parallel. After exposure, treated and untreated cells were harvested; RNA was isolated and processed for gene expression analysis as described above.

Statistical analysis. The correlation between different parameters was determined by simple regression analysis. 
Table II. Sensitivity to OXA, CDDP and $\mathrm{CuSO}_{4}$ in $\mathrm{HT} 29$ and OXA-resistant sublines as measured by MTT assay.

\begin{tabular}{lccccc}
\hline Cell line & $\mathrm{IC}_{50}{ }^{\mathrm{a}} \pm \mathrm{SD}$ & $\begin{array}{c}\mathrm{OXA}(\mu \mathrm{M}) \\
\mathrm{RI}^{\mathrm{b}}\end{array}$ & P-value & $\begin{array}{c}\mathrm{CDDP}(\mu \mathrm{M}) \\
\mathrm{IC}_{50}{ }^{\mathrm{a}} \pm \mathrm{SD}\end{array}$ & $\begin{array}{c}\mathrm{Cu}_{2} \mathrm{SO}_{4}(\mu \mathrm{M}) \\
\mathrm{IC}_{50}{ }^{\mathrm{a}} \pm \mathrm{SD}\end{array}$ \\
\hline HT29 & $7.0 \pm 0.9$ & - & 0.05 & $4.8 \pm 0.6$ & $498 \pm 32$ \\
HTOXAR1 & $10.3 \pm 1.6$ & 1.5 & 0.05 & $4.9 \pm 1.3$ & $475 \pm 32$ \\
HTOXAR2 & $17.0 \pm 3.6$ & 2.4 & 0.01 & $5.0 \pm 1.0$ & $500 \pm 21$ \\
HTOXAR3 & $35.8 \pm 5.0$ & 5.0 & 0.001 & $2.7 \pm 0.2$ & $447 \pm 81$ \\
\hline
\end{tabular}

${ }^{\mathrm{a}} \mathrm{IC}_{50}$, inhibitory concentration that kills $50 \%$ of cell population. Cells were exposed for $24 \mathrm{~h}$ to each drug. Cytotoxicity was determined $72 \mathrm{~h}$ after drug exposure by MTT. Data represent the mean \pm SD of at least three independent experiments performed with 8 wells at each drug concentration tested. ${ }^{b} \mathrm{RI}$, resistance index calculated as $\mathrm{IC}_{50}$ resistant $/ \mathrm{IC}_{50}$ sensitive cell line. $\mathrm{ND}$, not determined; $\mathrm{SD}$, standard deviation; $\mathrm{CDDP}$, cisplatin; OXA, oxaliplatin; $\mathrm{CuSO}_{4}$, copper sulfate. $\mathrm{P}<0.05$ was considered as a significant change in drug sensitivity (Student's t-test).

The statistical analysis was performed using SPSS 7.0. Two-sided P-values was calculated and a difference was considered as significant if $\mathrm{P}<0.05$. The inhibitory doses calculated per each cell line obtained with different drugs were compared using t-test of independent samples.

\section{Results}

Isolation of OXA-resistant cell lines. The isolation of cells resistant to OXA was started with an initial continuous exposure of HT29 colon cancer cells to $2 \mu \mathrm{M}$ OXA. After a period of high mortality, $20-30 \%$ of cells survived (data not shown). In the following passages, the cell number increased in the presence of OXA until cells showed doubling times (26-28 h) equivalent to untreated parental cells $(22-24 \mathrm{~h})$. The growth curve was then stable and no more net mortality occurred after confluence. A similar sequence of events followed with increasing concentrations, $4 \mu \mathrm{M}$ (HTOXAR2) and $14 \mu \mathrm{M}$ (HTOXAR3), of OXA. The OXA-resistant sublines were developed over a 10-month period. These cells were used for the present in vitro study.

Sensitivity of a colorectal cancer cell to OXA: resistance degree analysis. The sensitivity of OXA-sensitive (HT29) and -resistant (HTOXAR1, HTOXAR2, and HTOXAR3) colorectal cancer cells to OXA was evaluated by MTT assay and the data are summarized in Table II. OXA-resistant cells exhibited 1.5-, 2.4- and 5-fold resistance to OXA respectively, as compared to the sensitive parental HT29 cells.

The resistance index calculated as the ratio of $\mathrm{IC}_{50}$ of resistant cells: $\mathrm{IC}_{50}$ of sensitive cells was also evaluated by colony-formation assay (Fig. 1). Resistant sublines exhibited 2.6- to 7.8-fold resistance to OXA using this method. The $\mathrm{IC}_{50}$ concentrations for HT29, HTOXAR1, HTOXAR2 and HTOXAR3 were $2.7 \pm 1,7 \pm 2,9 \pm 3$ and $21 \pm 3 \mu \mathrm{M}$, respectively $(n=5)$.

Cross-resistance analysis: drug sensitivity to CDDP and copper. The sensitivity of HT29 and OXA-resistant cells to CDDP and copper was evaluated by MTT using 24-h drug exposure. As measured by this method, OXA-resistant cell lines did not exhibit cross-resistance to CDDP or copper (Table II).

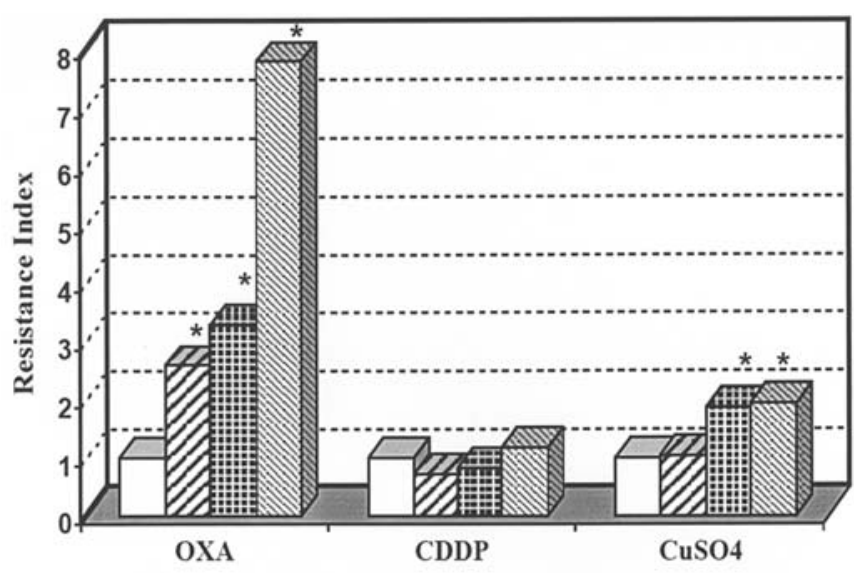

口HT29 घHTOXAR1 घHTOXAR2 \& HTOXAR3

\begin{tabular}{ccccccc}
\hline \multirow{2}{*}{ Cell line } & \multicolumn{2}{c}{ OXA } & \multicolumn{2}{c}{ CDDP } & \multicolumn{2}{c}{$\mathrm{CuSO}_{4}$} \\
\cline { 2 - 7 } & ${ }^{2} \mathrm{IC}_{50}$ & $P$ & ${ }^{2} \mathrm{IC}_{50}$ & $P$ & ${ }^{2} \mathrm{IC}_{50}$ & $P$ \\
\hline HT29 & $2.7 \pm 1.0$ & $\cdots$ & $3.6 \pm 1.1$ & $\cdots$ & $237 \pm 82$ & $\cdots$ \\
HTOXAR1 & $7.0 \pm 1.4$ & 0.03 & $2.6 \pm 0.9$ & 0.5 & $249 \pm 42$ & 0.8 \\
HTOXAR2 & $8.9 \pm 1.9$ & 0.002 & $3.0 \pm 1.0$ & 0.7 & $439 \pm 7.0$ & 0.04 \\
HTOXAR3 & $21.1 \pm 7.1$ & 0.01 & $4.2 \pm 1.1$ & 0.6 & $459 \pm 18$ & 0.01
\end{tabular}

Figure 1. Resistance index of OXA-resistant sublines to OXA, CDDP and $\mathrm{CuSO}_{4}$ determined by colony-formation assay. After OXA exposure (24 h) cells were grown in drug-free media until colonies became apparent. Data represent $\mathrm{IC}_{50}$ mean of resistant: $\mathrm{IC}_{50}$ mean of sensitive HT29 cell lines $\left({ }^{*} \mathrm{P}<0.05\right.$ was considered as a significant change in drug sensitivity; Student's t-test; ${ }^{a} \mathrm{IC}_{50}$, inhibitory concentration that kills $50 \%$ of cell population. Mean of a minimum of three independent experiments).

The cross-resistance index was also evaluated by colonyformation assay (Fig. 1). Whereas no significant changes were observed against CDDP, the acquisition of OXA resistance as measured by colony-formation assay significantly affected copper sensitivity $(\mathrm{P}<0.05)$ despite the relatively low degree of resistance to copper (1.8- and 1.9-fold cross-resistance for HTOXAR2 and HTOXAR3 respectively). It is noteworthy that, in each case, the magnitude of resistance to OXA was greater than that of copper. This result is consistent with prior studies of cross-resistance between platinum drugs and copper. 
Table III. Relative fold expression of OXA-resistant sublines as compared to parental HT29 cells.

\begin{tabular}{|c|c|c|c|c|c|c|c|}
\hline \multirow[b]{2}{*}{ Mechanism of resistance } & \multirow[b]{2}{*}{ Gene } & \multicolumn{6}{|c|}{ Fold expression versus parental HT29 cell line } \\
\hline & & HTOXAR1 & P-value & HTOXAR2 & P-value & HTOXAR3 & P-value \\
\hline Drug uptake & hCTR1 & $0.35 \pm 0.05$ & 0.002 & $0.37 \pm 0.03$ & 0.001 & $0.54 \pm 0.26$ & 0.015 \\
\hline \multirow[t]{3}{*}{ Drug efflux } & ATP7A & $0.32 \pm 0.01$ & 0.0001 & $0.37 \pm 0.03$ & 0.001 & $0.54 \pm 0.06$ & 0.003 \\
\hline & ATP7B & $0.44 \pm 0.07$ & 0.005 & $0.24 \pm 0.09$ & 0.005 & $0.35 \pm 0.10$ & 0.008 \\
\hline & MRP2 & Absent & - & Absent & - & Absent & - \\
\hline \multirow[t]{3}{*}{ Copper chaperones } & HAH1 & $0.81 \pm 0.04$ & 0.10 & $0.85 \pm 0.12$ & 0.13 & $0.90 \pm 0.12$ & 0.19 \\
\hline & CCS & $0.71 \pm 0.04$ & 0.05 & $1.41 \pm 0.07$ & 0.56 & $0.72 \pm 0.20$ & 0.04 \\
\hline & COX17 & $0.80 \pm 0.09$ & 0.21 & $0.61 \pm 0.10$ & 0.12 & $0.89 \pm 0.17$ & 0.29 \\
\hline \multirow[t]{2}{*}{ Drug detoxification } & GST $-\pi$ & $0.50 \pm 0.16$ & 0.037 & $0.50 \pm 0.10$ & 0.031 & $0.63 \pm 0.08$ & 0.015 \\
\hline & MT2A & $0.68 \pm 0.07$ & 0.09 & $0.90 \pm 0.28$ & 0.02 & $0.88 \pm 0.10$ & 0.13 \\
\hline \multirow[t]{4}{*}{ DNA repair } & ERCC1 & $0.44 \pm 0.08$ & 0.007 & $0.44 \pm 0.16$ & 0.010 & $0.51 \pm 0.14$ & 0.023 \\
\hline & XPD & $0.77 \pm 0.20$ & 0.05 & $0.57 \pm 0.03$ & 0.010 & $1.04 \pm 0.13$ & 0.46 \\
\hline & $\mathrm{XPF}$ & $0.46 \pm 0.07$ & 0.06 & $0.53 \pm 0.01$ & 0.20 & $0.52 \pm 0.14$ & 0.004 \\
\hline & CSB & $0.34 \pm 0.01$ & 0.009 & $0.47 \pm 0.06$ & 0.048 & $0.62 \pm 0.14$ & 0.02 \\
\hline Splicing regulation & SRPK1 & $0.52 \pm 0.01$ & 0.014 & $0.45 \pm 0.03$ & 0.023 & $0.35 \pm 0.03$ & 0.001 \\
\hline
\end{tabular}

$\mathrm{P}<0.05$ was considered as a significant change in gene expression. Values represent the mean $\pm \mathrm{SD}$ of at least three independent experiments. Two replicate reactions for each gene for each cell line were run within each experiment.

Gene expression analysis in OXA-sensitive and -resistant colorectal cancer cells in the absence of OXA. The expression of basal levels of a panel of 15 genes (ATP7B, ATP7A, hCTR1, CCS, COX17, HAH1, MRP2, GST- $\pi$, MT2A, ERCC1, CSB, XPD, XPF, SKRP1 and GAPDH, used as reference gene) was evaluated in the above cell lines by real-time RT-PCR in the absence of OXA. Relative mRNA expression for each gene was calculated according to the $2^{-\Delta \Delta C t}$ method (Table III). All the genes except MRP2 were expressed in the cell lines tested.

Our data show that in the absence of OXA, the resistant sublines exhibited lower expression levels of most of the genes analyzed as compared to the parental HT29 cell line (Table III). In particular, we observed low levels of genes involved in the NER pathway (ERCC1, CSB, XPD and XPF) and detoxification system (GST- $\pi$ and MT2A). Low expression levels of different genes are an indication that several pathways are affected in OXA resistance.

Copper transporters (hCTR1, ATP7A and ATP7B) seem to play a role in cytotoxicity of platinum agents. In the present study, we evaluated their implication in the acquisition of the resistance phenotype to OXA. We also evaluated whether the expression levels of these transporters as well as different chaperones involved in the copper trafficking inside the cell (COX17, CCS and HAH1) are involved in the acquisition of the OXA-resistance phenotype. At basal levels, OXA-resistant cells exhibited lower levels of ATP7A and ATP7B than parental HT29 cells. Expression levels of hCTR1 were also significantly diminished in the resistant cells (Table III, $\mathrm{P}<0.05)$. The expression levels of metallochaperones were similar or slightly diminished as compared to parent cells

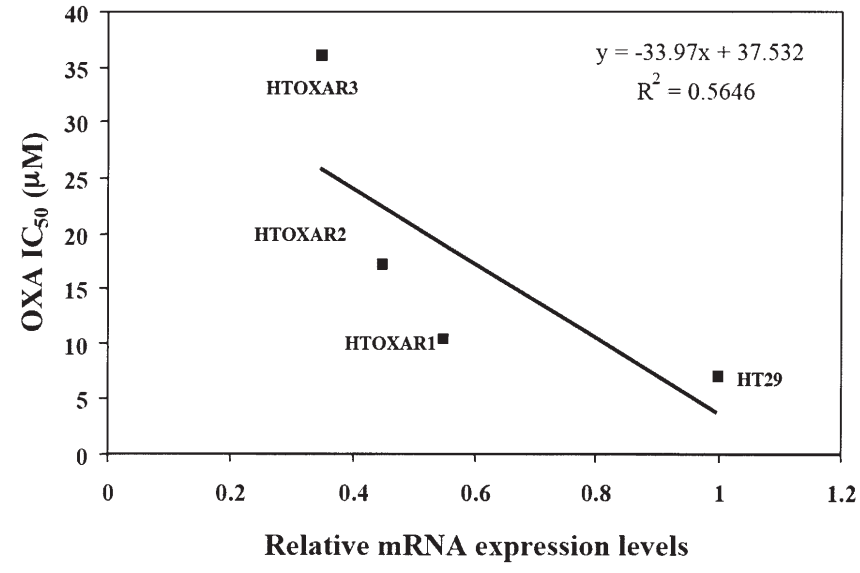

Figure 2. The OXA-resistant sublines exhibit lower SRPK1 expression levels than parental HT29 cell line. SRPK1 expression was evaluated by real-time quantitative reverse transcriptase-PCR on the parental HT29 cells and the OXA-resistant sublines and correlated with the cytotoxic effect of OXA determined by MTT assay. Results are the mean of at least three independent experiments.

with the exception of CCS that appeared upregulated in HTOXAR2 cells.

Previously, it was suggested that SRPK1 has a role determining sensitivity to CDDP. In the present study, we also evaluated the involvement of this kinase as a predictor of apoptosis measured by MTT assay after exposure to OXA. As shown in Table III, HTOXAR3 exhibited the lowest levels of SRPK1 correlating with its lack of response to OXA. In fact, we observed a correlation between sensitivity to OXA and relative higher gene expression levels of SRPK1 (Fig. 2). 

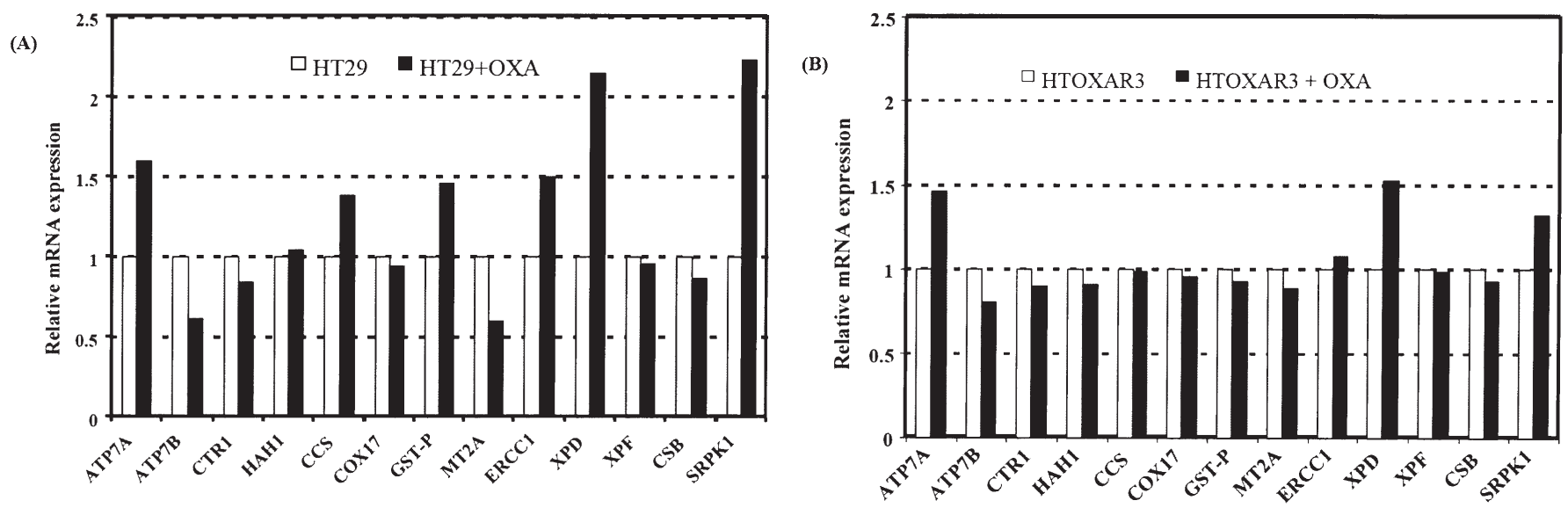

Figure 3. Gene expression changes in the presence of OXA. (A) HT29 cells and (B) HTOXAR3 cells were exposed to OXA at the dose with which we previously induced cell resistance in HTOXAR3 cells $(14 \mu \mathrm{M})$ for $48 \mathrm{~h}$. Values represent the mean of at least three independent experiments. Note the loss in dynamic expression range in the OXA-resistant subline.

Table IV. Relative fold gene expression changes in OXA-treated HT29 and HTOXAR3 cells as compared to their respective untreated control cells.

\begin{tabular}{|c|c|c|c|c|c|}
\hline \multirow[b]{2}{*}{ Mechanisms of resistance } & \multirow[b]{2}{*}{ Gene } & \multicolumn{4}{|c|}{ Fold expression changes in OXA-treated cells } \\
\hline & & HT29a & P-value & HTOXAR3 $^{\mathrm{b}}$ & P-value \\
\hline Drug uptake & hCTR1 & $0.84 \pm 0.25$ & 0.27 & $0.90 \pm 0.11$ & 0.21 \\
\hline \multirow[t]{3}{*}{ Drug efflux } & ATP7A & $1.60 \pm 0.34$ & 0.04 & $1.46 \pm 0.49$ & 0.10 \\
\hline & ATP7B & $0.62 \pm 0.15$ & 0.01 & $0.80 \pm 0.13$ & 0.02 \\
\hline & MRP2 & Absent & - & Absent & - \\
\hline \multirow[t]{3}{*}{ Copper chaperones } & HAH1 & $1.04 \pm 0.15$ & 0.97 & $0.99 \pm 0.25$ & 0.60 \\
\hline & CCS & $1.38 \pm 0.10$ & 0.02 & $0.91 \pm 0.10$ & 0.61 \\
\hline & COX17 & $0.94 \pm 0.23$ & 0.81 & $0.96 \pm 0.20$ & 0.97 \\
\hline \multirow[t]{2}{*}{ Drug detoxification } & GST $-\pi$ & $1.46 \pm 0.07$ & 0.007 & $0.93 \pm 0.13$ & 0.26 \\
\hline & MT2A & $0.60 \pm 0.15$ & 0.17 & $0.89 \pm 0.48$ & 0.18 \\
\hline \multirow[t]{4}{*}{ DNA repair } & ERCC1 & $1.50 \pm 0.26$ & 0.03 & $1.08 \pm 0.02$ & 0.64 \\
\hline & XPD & $2.15 \pm 0.82$ & 0.05 & $1.53 \pm 0.57$ & 0.09 \\
\hline & XPF & $0.96 \pm 0.25$ & 0.39 & $0.99 \pm 0.12$ & 0.58 \\
\hline & CSB & $0.87 \pm 0.12$ & 0.18 & $0.93 \pm 0.19$ & 0.40 \\
\hline Splicing regulation & SRPK1 & $2.23 \pm 0.80$ & 0.04 & $1.32 \pm 0.35$ & 0.29 \\
\hline
\end{tabular}

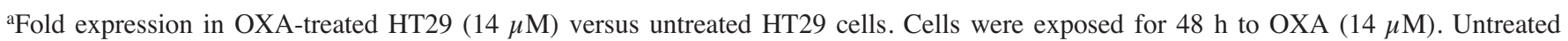
HT29 and HTOXAR3 cells were maintained in parallel. After exposure, treated and untreated cells were harvested and processed for gene expression analysis. Values represent the mean $\pm \mathrm{SD}$ of at least three independent experiments. Two replicate PCR reactions per each gene for each cell line were run within each experiment. ${ }^{\mathrm{b} F o l d}$ expression in OXA-treated HTOXAR3 $(14 \mu \mathrm{M})$ versus untreated HTOXAR3 cells. Highlighted genes altered in both HT29 and HTOXAR3 treated with OXA. P $<0.05$ was considered as a significant change in gene expression.

Gene expression analysis in the presence of OXA. To understand the importance of OXA-induced alterations in gene expression, we evaluated the expression of the 13 genes described above (with the exception of MRP2) in OXAtreated HT29 and HTOXAR3 cells. For this purpose, both cell lines were maintained in the presence of $14 \mu \mathrm{M}$ OXA corresponding to the dose required for resistance in HTOXAR3 (48-h exposure).
As shown in Fig. 3A, significant changes in gene expression ( 8 out of 13 evaluated genes; $62 \%$ ) were observed in HT29 cells treated with OXA as compared to untreated control cells (Table IV, P<0.05). Levels of ATP7A, CCS, GST- $\pi$, ERCC1, XPD and SRPK1 were upregulated whereas levels of ATP7B and MT2A were downregulated. Levels of hCTR1, HAH1, COX17, CSB and XPF, however, remained unaltered as compared to untreated control cells. 


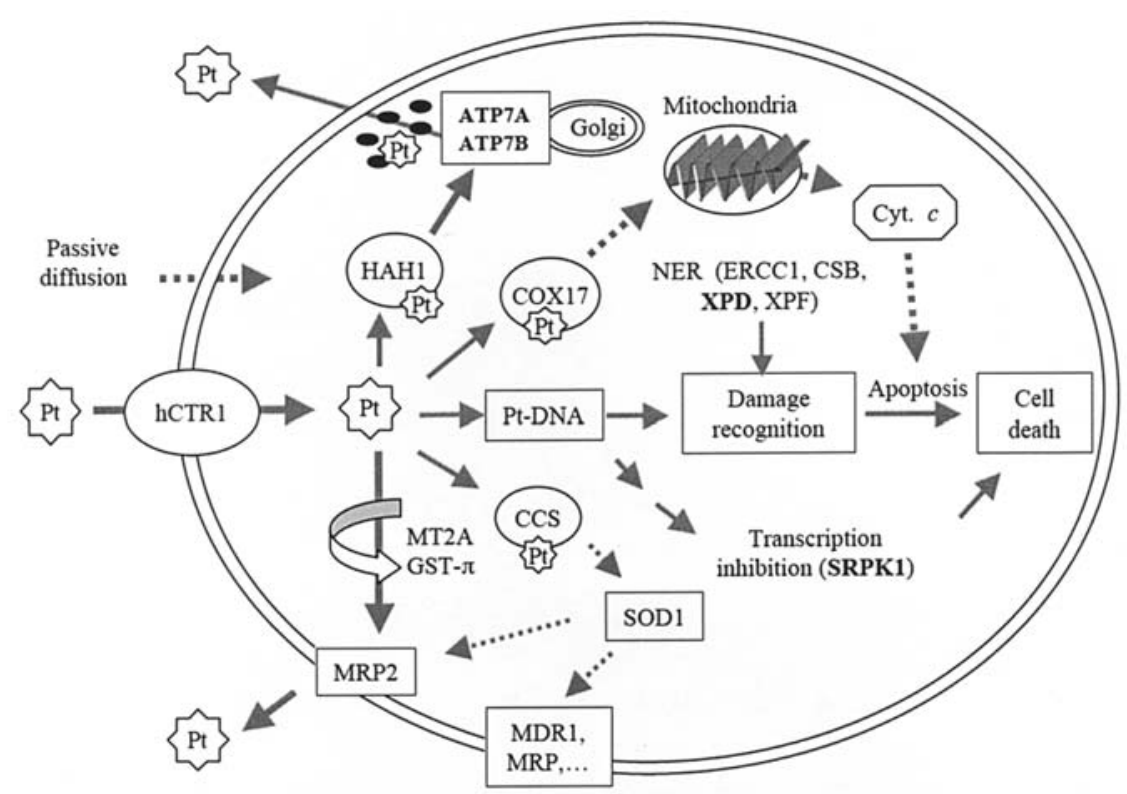

Figure 4. Schematic summary of the molecular determinants of OXA resistance evaluated in the present study. OXA enters a cell by passive diffusion and by the copper transporter, hCTR1. Inside the cell, OXA binds to copper chaperones HAH1, COX17 and CCS for specific delivery to Golgi compartment, mitochondria and $\mathrm{Cu} / \mathrm{Zn}-\mathrm{SOD} 1$, respectively. ATP7A and ATP7B may efflux OXA involving vesicle trafficking to the plasma membrane. OXA is susceptible to intracellular detoxification by reaction with glutathione and metallothioneins. Complexes with these nucleophiles are subjected to efflux by MRP2 and other MRP family members. OXA cytotoxicity is due to DNA-Pt adducts formation. Damaged DNA can be repaired primarily by the NER pathway. Highlighted genes were altered in both HT29 and HTOXAR3 cells treated with OXA.

Gene expression changes were also observed in OXAtreated HTOXAR3 (induced expression of ATP7A, XPD and SRPK1 and reduced expression of ATP7B) as compared to untreated HTOXAR3 cells (Fig. 3B). However, these changes occurred to a much lower extent compared to changes induced in sensitive HT29 cells treated with OXA (Table IV). Expression changes observed in HTOXAR3 cells exposed to OXA indicate that a partial gene-regulatory response to OXA is still present despite the lack of response to OXA measured by MTT assay. The overexpression of the copper transporter, ATP7A, suggests the involvement of the copper homeostatic system in OXA detoxification, whereas increased SRPK1 levels corroborated the role of this kinase in determining sensitivity to OXA.

Finally, as described in the previous section, levels of HTOXAR3 gene expression in both presence or absence of OXA, were mostly downregulated as compared to untreated HT29 cells with the exception of XPD, which appeared upregulated in both OXA-treated and untreated HTOXAR3 cells.

\section{Discussion}

The mechanisms underlying OXA resistance are still poorly understood. Most of the previous studies have focused on resistance to CDDP. Despite the differences between CDDP and OXA, the pharmacology of both drugs appears to be similar and OXA-resistant cells share some of the characteristics of CDDP-resistant cells $(3,6)$. Currently, it is accepted that resistance mechanisms include decreased accumulation of the drug, increased detoxification and repair, enhanced tolerance to DNA damage, alterations in pathways involved in cell cycle kinetics and apoptosis inactivation. In the present study, we have evaluated the expression levels of a panel of genes involved in platinum resistance in a sensitive colorectal cancer cell line (HT29) and its OXA-resistant sublines selected for acquired OXA resistance in vitro. We divided these genes into four categories as explained below and summarized in Fig. 4 and Tables III and IV.

Regulation of genes involved in copper trafficking and transport. Recent studies show that proteins involved in copper transport are also capable of transporting platinum agents (18). Low gene expression levels of hCTR1 are related to CDDP resistance, as this membrane protein mediates the active uptake of the drug. Moreover, the degradation of hCTR1 has been suggested in the presence of high levels of copper, CDDP and its analogues (27). In our study, OXA-resistant cells exhibited lower hCTR1 expression levels than the parental cell line, HT29 (Table III, P<0.05), suggesting that downregulation of hCTR1 is strongly involved in the acquisition of the resistance-phenotype in HT29 colon cancer cells and may be related to a decreased drug influx. Diminished levels of hCTR1 in resistant sublines also correlated with the crossresistance to copper (as measured by colony-assay). No relevant changes in the expression levels of this transporter were found upon exposure to OXA in HT29 and HTOXAR3 cells. hCTR 1 expression in HTOXAR3 resistant cells, however, remained downregulated even in the presence of OXA.

OXA-resistant cells exhibited low basal expression levels of ATP7A and ATP7B compared to parent HT29 (Table III). Our data are in agreement with previous studies that suggest that high expression levels of both transporters might confer hypersensitivity rather than resistance to OXA $(10,27)$. To our knowledge this is the first report describing the expression of copper transporters (ATP7A and ATP7B) in OXA-resistant cells. 
In response to OXA, increased levels of ATP7A, in both sensitive (HT29) and OXA-resistant (HTOXAR3) cells, were found. ATP7A overexpression is associated with poor survival after CDDP treatment (32). The fact that OXAtreated HTOXAR3 cells also showed slightly increased levels of ATP7A (although non-significant) suggests the presence of an intact molecular response to OXA in this cell line despite a lack of response to OXA as measured by MTT assay. ATP7B expression was significantly downregulated in HT29 and HTOXAR3 after exposure to OXA as compared to the respective untreated cells, corroborating the previous observation that ATP7B levels can be related to the sensitivity of these cells to OXA.

The role of the copper metallochaperones in OXA resistance was also evaluated. At basal levels, the three metallochaperones studied (HAH1, COX17 and CCS) in OXAresistant sublines exhibited similar levels to that observed in parental HT29 cells. Only CCS appeared slightly increased in HTOXAR2 suggesting a possible role for this gene in acquiring the OXA-resistance phenotype in this resistant subline. Exposure to OXA did not alter the expression levels of HAH1, CCS and COX17 in HTOXAR3 cells. An increase in CCS expression was observed in HT29 cells in response to OXA treatment. CCS is a specific protein that delivers copper from the plasma membrane to the cytoplasmic SOD1 enzyme, which requires copper ions as a cofactor for detoxifying reactive oxygen species $(21,22)$. The fact that CCS was induced in HT29 cells exposed to OXA but not in HTOXAR3 cells exposed to the same treatment suggests that the loss of CCS upregulation may be important in OXA resistance. It may implicate a role for SOD1 in the detoxification of OXA radical species but further studies analyzing the expression of this enzyme in sensitive as well as in OXA-resistant cancer cells are required to confirm this hypothesis. Finally, COX17 and HAH1 appeared not to have an important role in OXA resistance in this system.

Regulation of genes involved in the detoxification system. Basal expression levels of GST- $\pi$ appeared downregulated in OXA-resistant sublines as compared to the parental cells. Our data suggest that a diminished detoxification rather than an upregulation is involved in the acquisition of OXA resistance in the cell lines evaluated and it might be related to an enhanced tolerance to DNA damage. Our data are in agreement with previous results where no correlation could be established between basal levels of GST or GSH and sensitivity to CDDP or OXA in a panel of cell lines from different origins, including colon cancer cells (59).

The overexpression of metalloproteins (in particular MT2A) has been observed in CDDP-resistant cells $(42,43,60)$. In our study, the basal gene expression levels of MT2A were maintained or slightly decreased in the resistant sublines as compared to parental HT29 cells. To our knowledge, this is the first report including the levels of MT2A in relation with OXA resistance, although no relationship was apparent.

In the presence of OXA, only OXA-treated HT29 cells exhibited significant changes in expression of both genes (upregulation of GST- $\pi$ and downregulation of MT2A) as compared to respective untreated control cells, corroborating the role of the glutathione system in the active detoxification of OXA. Levels of both genes in HTOXAR3 remained unaltered in the presence of OXA at the dose with which we induced drug resistance in these cells. Therefore, the loss of the dynamic response of genes involved in detoxification in HTOXAR3 cells appears to be related to the ability of these cells to tolerate OXA pressure.

Regulation of genes involved in DNA repair. NER pathway is one of the major pathways involved in repair of DNA damage caused by platinum compounds. In fact, the ability of cells to repair DNA damage appears to be a critical determinant of CDDP sensitivity. High levels of specific proteins of this pathway (ERCC1 and XPD) are expressed in CDDP-resistant cells $(39,51)$. We have evaluated the expression of some NER genes involved in different steps of the repair pathway: CSB, which is recruited by RNA polymerase II, factor considered to be the sensor of DNA damage; XPD and XPF that are involved in the aperture of the DNA around the lesion and the excision of the damaged base(s) respectively and ERCC1 that forms an heterodimeric complex with XPF and is involved in 5 ' side incision of DNA adducts. In our study, the basal expression levels of all genes of NER pathway examined were diminished in OXA-resistant sublines as compared to HT29 cells. Only in HTOXAR3 (the most resistant cell line), XPD exhibited similar or increased expression levels in the absence of OXA. The basal levels of the rest of the NER genes evaluated (ERCC1, CSB and XPF) were low as compared to the parental cell line, HT29. A decrease in NER repair in OXA-resistant cells could indicate a diminished capacity of these cells to engage signaling that mediates the apoptosis induced by OXA. This fact might be related to the ability of these resistant populations to tolerate DNA damage.

OXA exposure induced the expression of NER genes in HT29 cells, in particular ERCC1 and XPD, as compared to untreated control cells. This suggests that repair of the damage induced by OXA is mediated by the NER repair system in colon cancer cell lines. Our data also confirm a correlation between ERCC1 and XPD gene expression as previously reported (61). No changes in ERCC1, CSB or XPF were observed in HTOXAR3 as compared to their respective untreated cells. However, the presence of OXA induced an increase in XPD expression levels in this cell line. Therefore, the upregulation of XPD may be involved in the acquisition of the OXA-resistant phenotype in HTOXAR3 cells. Whether the observed XPD overexpression in HTOXAR3 is due to an allelic gain or represents epigenetic regulation at transcriptional or translational levels of this gene requires further study. On the other hand, the upregulation of ERCC1 in response to OXA in HTOXAR3 is lost, suggesting that the molecular trigger for ERCC1 in resistant cells is lost. For XPD, however, the trigger mechanism is intact in both sensitive and resistant cell lines despite a difference in sensitivity to OXA.

Regulation in genes involved in RNA splicing regulation. Finally, we also evaluated the expression level of SRPK1, a nuclear protein kinase specifically related to the transcription inhibition induced by platinum agents. SRPK1 and their targets are thought to be the key regulators of RNA processing in both constitutive and alternative mRNA splicing in mammalian cells (54). High levels of gene expression of 
Table V. Correlation between drug resistance and selected gene expression.

\begin{tabular}{|c|c|c|c|c|c|c|}
\hline $\begin{array}{l}\text { Molecular } \\
\text { mechanism }\end{array}$ & $\begin{array}{l}\text { Tumor } \\
\text { type }\end{array}$ & Protein & $\begin{array}{l}\text { Detection } \\
\text { method }\end{array}$ & Treatment & Outcome & Refs. \\
\hline \multirow[t]{4}{*}{$\begin{array}{l}\text { Genes involved in } \\
\text { copper trafficking } \\
\text { and transport }\end{array}$} & $\begin{array}{l}\text { Ovarian, prostate, } \\
\text { breast, kidney, } \\
\text { pancreas, liver, } \\
\text { thyroid, ovary }\end{array}$ & $\begin{array}{l}\text { АТР7B, } \\
\text { АТР7A }\end{array}$ & $\begin{array}{l}\text { IHC, } \\
\text { RT-PCR }\end{array}$ & CDDP & $\begin{array}{l}\text { Increased expression } \\
\text { correlated with CDDP } \\
\text { resistance }\end{array}$ & $(28-32)$ \\
\hline & Colorectal, lung & $\begin{array}{l}\text { MDR-1, } \\
\text { MRP1-6 }\end{array}$ & $\begin{array}{l}\text { RT-PCR, } \\
\text { IHC }\end{array}$ & $\begin{array}{l}\text { CDDP, } \\
5 F U \\
\text { MYC, } \\
\text { DOX }\end{array}$ & $\begin{array}{l}\text { Upregulation of MRP2 } \\
\text { correlated with CDDP } \\
\text { resistance }\end{array}$ & $(9,66,67)$ \\
\hline & Ovarian & hCTR1 & RT-PCR & $\begin{array}{l}\mathrm{Pt} \\
\text { analogues }\end{array}$ & $\begin{array}{l}\text { Downregulation of } \\
\text { CTR1 correlated with } \\
\text { platinum-resistance }\end{array}$ & $(25,27)$ \\
\hline & Lung & COX17 & $\begin{array}{l}\text { RT-PCR, } \\
\text { IHC }\end{array}$ & Untreated & $\begin{array}{l}\text { Upreguation of COX17 } \\
\text { correlated with poor } \\
\text { prognosis }\end{array}$ & $(68)$ \\
\hline $\begin{array}{l}\text { Genes involved } \\
\text { in detoxification } \\
\text { system }\end{array}$ & $\begin{array}{l}\text { Ovarian, bladder, } \\
\text { leukaemia, lung }\end{array}$ & $\begin{array}{l}\text { GST, } \\
\text { MT2A }\end{array}$ & $\begin{array}{l}\text { RT-PCR, } \\
\text { WB }\end{array}$ & CDDP & $\begin{array}{l}\text { Increased expression } \\
\text { correlated with poor } \\
\text { prognosis and intrinsic } \\
\text { resistance }\end{array}$ & $(36-38,42,43,59,60)$ \\
\hline $\begin{array}{l}\text { Genes involved } \\
\text { in DNA repair }\end{array}$ & $\begin{array}{l}\text { Ovarian, lung, } \\
\text { colorectal }\end{array}$ & $\begin{array}{l}\text { ERCC1, } \\
\text { XPD, } \\
\text { XPF, } \\
\text { CSB }\end{array}$ & RT-PCR & Pt-based & $\begin{array}{l}\text { Increased levels correlated } \\
\text { with platinum-based } \\
\text { chemotherapy resistance }\end{array}$ & $(39,45-51,59,61)$ \\
\hline $\begin{array}{l}\text { Genes involved } \\
\text { in RNA splicing } \\
\text { regulation }\end{array}$ & $\begin{array}{l}\text { Ovarian, } \\
\text { testicular } \\
\text { germ cell }\end{array}$ & SRPK1 & $\begin{array}{l}\text { IHC, WB, } \\
\text { PCR }\end{array}$ & CDDP & $\begin{array}{l}\text { Downregulation of } \\
\text { SRPK1 correlated with } \\
\text { platinum-resistance }\end{array}$ & $(52,62)$ \\
\hline
\end{tabular}

SRPK1 have been detected in testicular cancer, one of the most CDDP-sensitive tumors. In fact, SRPK1 is considered as a marker of response to CDDP (62), in the sense that CDDP induces high levels of this protein that are required to phosphorylate different substrates (SR-proteins), altering their subnuclear localization and ultimately causing an inhibition of RNA splicing $(53,63)$. Data in our study suggest, for the first time, that SRPK1 is not only involved in CDDP sensitivity but also in OXA sensitivity. OXA-resistant sublines exhibited lower levels of SRPK1 as compared to the parental HT29 cell line (Table III). In addition, a correlation was observed between the acquired resistance degree of these sublines and the levels of expression of SRPK1: the lower SRPK1 gene levels, the higher $\mathrm{IC}_{50}$ (dose required to kill $50 \%$ of the cells) (Fig. 2). In the presence of OXA, HT29 cells demonstrated a $>2$-fold increase in levels of SRPK1 expression (Table IV, $\mathrm{P}<0.05$ ), suggesting a role for SRPK1 as a marker of response to OXA in both, sensitive and OXAresistant colorectal cancer tumors. Further studies blocking the RNA expression of SRPK1 in our cell model are required to conclude the association between drug resistance and SRPK1 expression.
In summary, our study shows the following: a) cell lines resistant to OXA as measured by MTT and confirmed by colony-formation assays can be induced by exposure to OXA; b) the expression of many genes putatively involved in platinum resistance is decreased upon induction of OXA resistance in HT29 cells; c) when HT29 cells are exposed to OXA, the resultant expression of ATP7A, CCS, GST- $\pi$, ERCC1, XPD and SRPK1 is significantly increased while that of ATP7B is significantly decreased; and d) exposure to OXA in HTOXAR3 results in increased expression of ATP7A, XPD and SRPK1 and decreased ATP7B expression whereas CCS, GST- $\pi$ and ERCC 1 are unchanged.

The implications of these findings include the following: a) OXA exposure in resistant cell lines results in loss of the dynamic response of CCS, GST- $\pi$ and ERCC1 to OXA exposure; and b) OXA exposure in resistant cells results in maintenance of the dynamic response of ATP7A, ATP7B, XPD and SRPK1 to OXA exposure. This bimodal response to OXA in these cells implies two processes: the loss of molecular changes potentially important in response to OXA and the maintenance of processes that are no longer effective in inducing apoptosis in resistant cells. Each of these processes 
is likely to have underpinning mechanisms upstream and downstream of the molecules involved. The elucidation of these mechanisms in the model system and human tumors obtained before and after treatment with OXA may expand the understanding of resistance to this compound. This study provides the basis for further evaluation of these putative markers of OXA response and resistance in patients with colorectal cancer who are candidates for treatment with OXA.

Further studies involving protein evaluation are in progress in our laboratory to corroborate the gene expression. However, the provided data concerning gene expression in the present study is particularly important for clinical studies using a subset of these genes as potential markers to predict response in colorectal cancer patients who are candidates for treatment with OXA. This point is of particular relevance because of recent improvements in molecular techniques to isolate small quantities of mRNA from tumors (including paraffin-embedded samples) and real-time PCR as compared to other techniques such as immunohistochemistry. This latter technique is problematic for clinical studies because of the following: a) the lack of antibodies for many proteins; b) the lack of uniform quality control in commercially available antibodies; c) the lack of uniform protocols within and across different laboratories; d) the requirement of large samples; and e) a high degree of variability in the technique across different studies.

The genes evaluated in the present study were selected on the basis of the potential relationship of their expression with platinum-resistance. For example, Staunton et al (64) demonstrated that upregulation of mRNA transcripts is linked to chemotherapy response. Recently different studies using microarray technologies revealed interesting correlations between gene expression and drug-resistance (65). In fact, the mRNA expression in most of the genes evaluated in the present study (Table V) is considered as a relevant parameter for in vivo chemoresistance in many tumor types. Moreover, the present findings that mRNA transcripts of certain genes can increase after platinum-based chemotherapy is initiated indicate that assessment of gene expression should be considered not only at baseline but also during treatment.

Understanding the mechanisms involved in platinum resistance is therefore of paramount importance in devising future strategies to circumvent OXA resistance more effectively and to translate them into durable clinical responses.

\section{References}

1. Armand JP, Boige V, Raymond E, Fizazi K, Faivre S and Ducreux M: Oxaliplatin in colorectal cancer: an overview. Semin Oncol 27: 96-104, 2000.

2. Raymond E, Lawrence R, Izbicka E, Faivre S and von Hoff DD: Activity of oxaliplatin against human tumor colony-forming units. Clin Cancer Res 4: 1021-1029, 1998.

3. Wang D and Lippard SJ: Cellular processing of platinum anticancer drugs. Nat Rev Drug Discov 4: 307-320, 2005.

4. Sobrero A, Kerr D, Glimelius B, van Cutsem E, Milano G, Pritchard DM, Rougier P and Aapro M: New directions in the treatment of colorectal cancer: a look to the future. Eur J Cancer 36: 559-566, 2000.

5. Chau I and Cunningham D: Adjuvant therapy in colon cancer: current status and future directions. Cancer Treat Rev 28: 223-236, 2002.

6. Ohmichi M, Hayakawa J, Tasaka K, Kurachi H and Murata Y: Mechanisms of platinum drug resistance. Trends Pharmacol Sci 26: 113-116, 2005.
7. Judson I and Kelland LR: New developments and approaches in the platinum arena. Drugs 59 (suppl 4): 29-37, 2000.

8. Giaccone G: Clinical perspectives on platinum resistance. Drugs 59 (suppl 4): 9-37, 2000.

9. Siddik ZH: Cisplatin: mode of cytotoxic action and molecular basis of resistance. Oncogene 22: 7265-7279, 2003.

10. Mishima M, Samimi G, Kondo A, Lin X and Howell SB: The cellular pharmacology of oxaliplatin resistance. Eur J Cancer 38: $1405-1412,2002$.

11. Yoshida M, Khokhar AR and Siddik ZH: Biochemical pharmacology of homologous alicyclic mixed amine platinum(II) complexes in sensitive and resistant tumor cell lines. Cancer Res 54: 3468-3473, 1994.

12. Borst P, Evers R, Kool M and Wijnholds J: A family of drug transporters: the multidrug resistance-associated proteins. J Natl Cancer Inst 92: 1295-1302, 2000.

13. Gately DP and Howell SB: Cellular accumulation of the anticancer agent cisplatin: A review. Br J Cancer 67: 1171-1176, 1993.

14. Katano K, Safaei R, Samimi G, Holzer A, Rochdi M and Howell SB: The copper export pump ATP7B modulates the cellular pharmacology of carboplatin in ovarian carcinoma cells. Mol Pharmacol 64: 466-473, 2003.

15. Safaei R, Katano K, Samimi G, Naerdemann W, Stevenson JL, Rochdi M and Howell SB: Cross-resistance to cisplatin in cells with acquired resistance to copper. Cancer Chemother Pharmacol 53: 239-246, 2004.

16. Katano K, Kondo A, Safaei R, Holzer A, Samimi G, Mishima M, Kuo YM, Rochdi M and Howell SB: Acquisition of resistance to cisplatin is accompanied by changes in the cellular pharmacology of copper. Cancer Res 62: 6559-6565, 2002.

17. Kruh GD: Lustrous insights into cisplatin accumulation: copper transporters. Clin Cancer Res 9: 5807-5809, 2003.

18. Safaei R and Howell SB: Copper transporters regulate the cellular pharmacology and sensitivity to Pt drugs. Crit Rev Oncol Hematol 53: 13-23, 2005.

19. Moeller L: Characterization of hCTR1 gene: genomic organization, functional expression and identification of highly homologous processed gene. Gene 257: 13-22, 2000.

20. Markossian KA and Kurganov BI: Copper chaperones, intracellular copper trafficking proteins. Function, structure and mechanism of action. Biochemistry 68: 827-837, 2003.

21. Field LS, Luk E and Culotta VC: Copper chaperones: personal escorts for metal ions. J Bioenerg Biomembr 34: 373-379, 2002.

22. Hamza I and Gitlin JD: Copper chaperones for cytochrome c oxidase and human disease. J Bioenerg Biomembr 34: 381-388, 2002.

23. Ishida S, Lee J, Thiele DJ and Herskowitz I: Uptake of the anticancer drug cisplatin mediated by the copper transporter Ctr1 in yeast and mammals. Proc Natl Acad Sci USA 99: 14298-14302, 2002.

24. Lin X, Okuda T, Holzer A and Howell SB: The copper transporter CTR1 regulates cisplatin uptake in Saccharomyces cerevisiae. Mol Pharmacol 62: 1154-1159, 2002.

25. Holzer AK, Samimi G, Katano K, Naerdemann W, Lin X, Safaei R and Howell SB: The copper influx transporter hCTR1 regulates the uptake of cisplatin in human ovarian carcinoma cells. Mol Pharmacol 66: 817-823, 2004.

26. Solioz M and Vulpe C: CPx-type ATPases: a class of P-type ATPases that pump heavy metals. Trends Biochem Sci 21: 237-241, 1996.

27. Samimi G, Katano K, Holzer AK, Safaei R and Howell SB: Modulation of the cellular pharmacology of cisplatin and its analogs by the copper exporters ATP7A and ATP7B. Mol Pharmacol 66: 25-32, 2004.

28. Kanzaki A, Toi M, Neamati N, Miyashita H, Oubu M, Nakayama K, Bando H, Ogawa K, Mutoh M, Mori S, Terada K, Sugiyama T, Fukumoto $M$ and Takebayashi Y: Coppertransporting P-type adenosine triphosphatase (ATP7B) is expressed in human breast carcinoma. Jpn J Cancer Res 93: 70-77, 2002

29. Ohbu M, Ogawa K, Konno S, Kanzaki A, Terada K, Sugiyama T and Takebayashi Y: Copper-transporting P-type adenosine triphosphatase (ATP7B) is expressed in human gastric carcinoma. Cancer Lett 189: 33-38, 2003.

30. Nakayama K, Kanzaki A, Ogawa K, Miyazaki K, Neamati N and Takebayashi Y: Copper-transporting P-type adenosine triphosphatase (ATP7B) as a cisplatin based chemoresistance marker in ovarian carcinoma: comparative analysis with expression of MDR1, MRP1, MRP2, LRP and BCRP. Int J Cancer 101: 488-495, 2002. 
31. Nakayama K, Kanzaki A, Terada K, Mutoh M, Ogawa K, Sugiyama T, Takenoshita S, Itoh K, Yaegashi N, Miyazaki K, Neamati $\mathrm{N}$ and Takebayashi Y: Prognostic value of the $\mathrm{Cu}-$ transporting ATPase in ovarian carcinoma patients receiving cisplatin-based chemotherapy. Clin Cancer Res 10: 2804-2811, 2004.

32. Samimi G, Varki NM, Wilczynski S, Safaei R, Alberts DS and Howell SB: Increase in expression of the copper transporter ATP7A during platinum drug-based treatment is associated with poor survival in ovarian cancer patients. Clin Cancer Res 9: 5853-5859, 2003

33. Kweekel DM, Gelderblom H and Guchelaar HJ: Pharmacology of oxaliplatin and the use of pharmacogenomics to individualize therapy. Cancer Treat Rev 31: 90-105, 2005.

34. Jansen BA, Brouwer J and Reedijk J: Glutathione induces cellular resistance against cationic dinuclear platinum anticancer drugs. J Inorg Biochem 89: 197-202, 2002.

35. Eastman A: Cross-linking of glutathione to DNA by cancer chemotherapeutic platinum coordination complexes. Chem Biol Interact 61: 241-248, 1987.

36. Ishikawa T and Ali-Osman F: Glutathione-associated cisdiamminedichloroplatinum(II) metabolism and ATP-dependent efflux from leukemia cells. Molecular characterization of glutathione-platinum complex and its biological significance. J Biol Chem 268: 20116-20125, 1993.

37. Goto S, Iida T, Cho S, Oka M, Kohno S and Kondo T: Overexpression of glutathione S-transferase pi enhances the adduct formation of cisplatin with glutathione in human cancer cells. Free Radic Res 31: 549-558, 1999.

38. El-Akawi Z, Abu-Hadid M, Perez R, Glavy J, Zdanowicz J, Creaven PJ and Pendyala L: Altered glutathione metabolism in oxaliplatin resistant ovarian carcinoma cells. Cancer Lett 105: 5-14, 1996.

39. Rosell R, Taron M, Barnadas A, Scagliotti G, Sarries C and Roig B: Nucleotide excision repair pathways involved in cisplatin resistance in non-small cell lung cancer. Cancer Control 10: 297-305, 2003.

40. Kelland LR: Preclinical perspectives on platinum resistance. Drugs 59 (suppl 4): 1-38, 2000.

41. Rudin CM, Yang Z, Schumaker LM, Vander Weele DJ, Newkirk K, Egorin MJ, Zuhowski EG and Cullen KJ: Inhibition of glutathione synthesis reverses Bcl-2-mediated cisplatin resistance. Cancer Res 63: 312-318, 2003.

42. Kasahara K, Fujiwara Y, Nishio K, Ohmori T, Sugimoto Y, Komiya K, Matsuda T and Saijo N: Metallothionein content correlates with the sensitivity of human small cell lung cancer cell lines to cisplatin. Cancer Res 51: 3237-3242, 1991.

43. Vandier D, Calvez V, Massade L, Gouyette A, Mickley L, Fojo T and Rixe O: Transactivation of the metallothionein promoter in cisplatin-resistant cancer cells: a specific gene therapy strategy. J Natl Cancer Inst 92: 642-647, 2000.

44. Furuta T, Ueda T, Aune G, Sarasin A, Kraemer KH and Pommier Y: Transcription-coupled nucleotide excision repair as a determinant of cisplatin sensitivity of human cells. Cancer Res 62: 4899-4902, 2002.

45. Damia G, Guidi G and D'Incalci M: Expression of genes involved in nucleotide excision repair and sensitivity to cisplatin and melphalan in human cancer cell lines. Eur J Cancer 34: 1783-1788, 1998

46. Selvakumaran M, Pisarcik DA, Bao R, Yeung AT and Hamilton TC: Enhanced cisplatin cytotoxicity by disturbing the nucleotide excision repair pathway in ovarian cancer cell lines. Cancer Res 63: 1311-1316, 2003.

47. Dabholkar M, Bostick-Bruton F, Weber C, Bohr VA, Egwuagu C and Reed E: ERCC1 and ERCC2 expression in malignant tissues from ovarian cancer patients. J Natl Cancer Inst 84: 1512-1517, 1992.

48. Codegoni AM, Broggini M, Pitelli MR, Pantarotto M, Torri V, Mangioni $\mathrm{C}$ and D'Incalci $\mathrm{M}$ : Expression of genes of potential importance in the response to chemotherapy and DNA repair in patients with ovarian cancer. Gynecol Oncol 65: 130-137, 1997.

49. Reed E: Platinum-DNA adduct, nucleotide excision repair and platinum based anti-cancer chemotherapy. Cancer Treat Rev 24: 331-344, 1998

50. Lord RV, Brabender J, Gandara D, Alberola V, Camps C, Domine M, Cardenal F, Sanchez JM, Gumerlock PH, Taron M, Sanchez JJ, Danenberg KD, Danenberg PV and Rosell R: Low ERCC1 expression correlates with prolonged survival after cisplatin plus gemcitabine chemotherapy in non-small cell lung cancer. Clin Cancer Res 8: 2286-2291, 2002.
51. Shirota Y, Stoehlmacher J, Brabender J, Xiong YP, Uetake H, Danenberg KD, Groshen S, Tsao-Wei DD, Danenberg PV and Lenz HJ: ERCC1 and thymidylate synthase mRNA levels predict survival for colorectal cancer patients receiving combination oxaliplatin and fluorouracil chemotherapy. J Clin Oncol 19: 4298-4304, 2001.

52. Schenk PW, Boersma AW, Brandsma JA, Den Dulk H, Burger H, Stoter G, Brouwer J and Nooter K: SKY1 is involved in cisplatininduced cell kill in Saccharomyces cerevisiae and inactivation of its human homologue, SRPK1, induces cisplatin resistance in a human ovarian carcinoma cell line. Cancer Res 61: 6982-6986, 2001.

53. Umehara H, Nishii Y, Morishima M, Kakehi Y, Kioka N, Amachi T, Koizumi J, Hagiwara M and Ueda K: Effect of cisplatin treatment on speckled distribution of a serine/argininerich nuclear protein CROP/Luc7A. Biochem Biophys Res Commun 301: 324-329, 2003.

54. Yeakley JM, Tronchere H, Olesen J, Dyck JA, Wang HY and Fu XD: Phosphorylation regulates in vivo interaction and molecular targeting of serine/arginine-rich pre-mRNA splicing factors. J Cell Biol 145: 447-455, 1999.

55. Alley MC, Scudiero DA, Monks A, Hursey ML, Czerwinski MJ, Fine DL, Abbott BJ, Mayo JG, Shoemaker RH and Boyd MR: Feasibility of drug screening with panels of human tumor cell lines using a microculture tetrazolium assay. Cancer Res 48: 589-601, 1988.

56. Plasencia C, Rooney PH, Taron M, Martinez-Balibrea E, McLeod HL and Abad A: Chromosomal imbalance maps of human 5FU-resistant colorectal cancer cell lines: implications in the analysis of 5FU-acquired resistance mechanisms. Int J Oncol 22: 945-953, 2003.

57. Munshi A, Hobbs M and Meyn RE: Clonogenic cell survival assay. Methods Mol Med 110: 21-28, 2005.

58. Giulietti A, Overbergh L, Valckx D, Decallonne B, Bouillon R and Mathieu C: An overview of real-time quantitative PCR: applications to quantify cytokine gene expression. Methods 25: 386-401, 2001.

59. Arnould S, Hennebelle I, Canal P, Bugat R and Guichard S: Cellular determinants of oxaliplatin sensitivity in colon cancer cell lines. Eur J Cancer 39: 112-119, 2003.

60. Surowiak P, Materna V, Kaplenko I, Spaczynski M, Dietel M, Lage $\mathrm{H}$ and Zabel M: Augmented expression of metallothionein and glutathione S-transferase pi as unfavourable prognostic factors in cisplatin-treated ovarian cancer patients. Virchows Arch 447: 626-633, 2005

61. Vogel U, Dybdahl M, Frentz G and Nexo BA: DNA repair capacity: inconsistency between effect of overexpression of five NER genes and the correlation to mRNA levels in primary lymphocytes. Mutat Res 461: 197-210, 2000.

62. Schenk PW, Stoop H, Bokemeyer C, Mayer F, Stoter G, Oosterhuis JW, Wiemer E, Looijenga LH and Nooter K: Resistance to platinum-containing chemotherapy in testicular germ cell tumors is associated with downregulation of the protein kinase SRPK1. Neoplasia 6: 297-301, 2004.

63. Lallena MJ and Correas I: Transcription-dependent redistribution of nuclear protein 4.1 to SC35-enriched nuclear domains. J Cell Sci 110: 239-247, 1997

64. Staunton JE, Slonim DK, Coller HA, Tamayo P, Angelo MJ, Park J, Scherf U, Lee JK, Reinhold WO, Weinstein JN, Mesirov JP, Lander ES and Golub TR: Chemosensitivity prediction by transcriptional profiling. Proc Natl Acad Sci USA 98: 10787-10792, 2001.

65. Kang H: Identification of genes with differential expression in acquired drug-resistant gastric cancer cells using high-density oligonucleotide microarrays. Clin Cancer Res 10: 272-284, 2004.

66. Hinoshita E, Uchiumi T, Taguchi K, Kinukawa N, Tsuneyoshi M, Maehara Y, Sugimachi K and Kuwano M: Increased expression of an ATP-binding cassette superfamily transporter, multidrug resistance protein 2, in human colorectal carcinomas. Clin Cancer Res 6: 2401-2407, 2000.

67. Campling BG, Young LC, Baer KA, Lam YM, Deeley RG, Cole SP and Gerlach JH: Expression of the MRP and MDR1 multidrug resistance genes in small cell lung cancer. Clin Cancer Res 3: 115-122, 1997.

68. Suzuki C, Daigo Y, Kikuchi T, Katagiri T and Nakamura Y: Identification of COX17 as a therapeutic target for non-small cell lung cancer. Cancer Res 63: 7038-7041, 2003. 